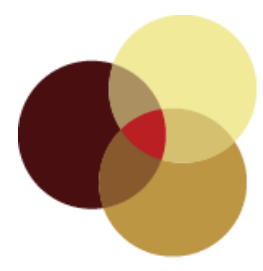

\title{
About Contemporaneity
}

Contemporaneity: Historical Presence in Visual Culture is a journal of visual culture that explores how temporality has acquired visual form in a range of different cultural and historical settings. Devoted to presenting the diverse ways in which time becomes visual as well as how visual culture conditions time and our perception of it, Contemporaneity aims to publish work that grapples with the question of how cultures worldwide and throughout history use images to record, define, and confront their historical context and lived experience of the temporal.

As historicist master narratives and totalizing theories of the end of history lose their relevance for today's scholars, it has become clear that time is not an empty duration unaffected by the events that fill it. In the past century, we became aware that different cultures past and present conceive of and value time differently, and that time itself has a history. Time is neither homogenous nor blank but is constructed, contested, multiple, and asymmetrical, and, moreover, there are many ways of being in time and belonging to it (or not belonging to it) that coexist contemporaneously. Taking this complex understanding of temporality as its structuring theme, Contemporaneity rethinks the relationship between visual culture and time and facilitates understanding of how the present was, is, and will be experienced differently depending on both individual and social histories.

New scholarship on pre-modern art has increasingly taken time into account, examining cultural notions about the present and their profound effects on image-making. As we become ever more aware of the disjointedness of our current temporal condition, the need for Contemporaneity becomes clearer and clearer. Sharpening our sense of how images from the past construe relationships to, with, through, in, and against time will help us to grasp features of our own time, such as the persistence of the past in the present or the lost faith in a utopian future. Contemporaneity is published in the conviction that all images have something unique to tell us about our historical condition, and that they configure the plural temporalities of our contemporaneity in ways that deserve our closest attention and most rigorous scholarship.

We welcome your involvement as both readers and contributors. Contemporaneity will be published annually in the spring. Submissions should be sent by August 30 each year. We support scholarship on art, architecture, photography, film, and new media as well as texts and projects by practitioners working in these areas.

Cristina Albu, Robert Bailey, Saskia Beranek, Brianne Cohen, Heidi Cook, Amy Cymbala, Rachel Miller, Yuki Morishima, Sara Sumpter are the Editors of Contemporaneity: Historical Presence in Visual Culture. 


\section{(c)) EY-NC-ND}

This work is licensed under a Creative Commons Attribution-Noncommercial-No Derivative Works 3.0 United States License.

\section{ULIS D-Sont}

This journal is operated by the University Library System of the University of Pittsburgh as part of its D-Scribe Digital Publishing Program, and is co-sponsored by the University of Pittsburgh Press. 